\title{
OS LIMITES DA CAPACIDADE REGULATÓRIA DO ESTADO NAS DINÂMICAS DA VIOLÊNCIA DOS ATORES NÃO ESTATAIS GLOBAIS
}

\section{Maria Luiza Roman Folle ${ }^{1}$}

\section{RESUMO:}

O presente estudo consiste em abordar os limites da capacidade regulatória do Estado nas dinâmicas da violência dos atores não estatais globais. Identifica-se a sociedade global, apresentando-a como o cenário de insurgência dos tipificados atores não estatais,demonstrando as dinâmicas de violências exercidas pelas organizações criminosas e terroristas e seus desdobramentos negativos. A atuação dos atores não estatais a nível global transcende o alcance atual da capacidade regulatória do Estado, tornando-o altamente vulnerável, seja pela real fragmentação de sua soberania, seja pela inércia do Direito diante do fenômeno multifacetado da globalização, transformando assim o estatocentrismo enfático presente nas Relações Internacionais tradicionais.

Palavras-chave: Estado;violência;atores não estatais; regulação jurídica; globalização.

\section{THE LIMITS OF THE REGULATORY CAPACITY OF THE STATE IN THE DYNAMICS OF THE VIOLENCE OF NON-STATE GLOBAL ACTORS}

\begin{abstract}
:
The present study consists of addressing the limits of the State's regulatory capacity in the dynamics of violence of global non-state actors. It identifies the global society, presenting it as the scenario of insurgency of the typified non-state actors, demonstrating the dynamics of violence perpetrated by criminal and terrorist organizations and their negative developments. The performance of non-state actors globally transcends the current scope of the state's regulatory capacity, making it highly vulnerable, either by the real fragmentation of its sovereignty or by the inertia of the law in the face of the multifaceted phenomenon of globalization, thus transforming emphatic statocentrism present in traditional international relations.
\end{abstract}

Keywords: State; violence; Non-state actors; legal regulation; globalization.

\section{INTRODUÇÃO}

A evolução dos conceitos que envolvem desde a sociedade internacional à sociedade global e, ainda, a maior interação entre seus atores não estatais estão gerando inúmeros estudos acadêmicos, por se tratar de temas contemporâneos complexos. Um dos recortes que se destaca é o protagonismo dos atores não estatais de atuação violenta, que,interconectados por meio de redes clandestinas, emanam grande poder e capacidade de influenciar decisões

\footnotetext{
${ }^{1}$ Mestranda em Direito pela Unochapecó. Bolsista Fapesc. Membro do grupo de estudos Membro do Grupo de Pesquisa Relações Internacionais, Direito e Poder: cenários e protagonismo dos atores estatais e não estatais da UNOCHAPECÓ, com registro no Diretório dos Grupos de Pesquisa do CNPq. Pesquisadora voluntária e integrante do Grupo de Estudos em Relações Internacionais: Poder, Globalização e Atores, da Unochapeco.
} 
dos atores estatais ao utilizarem o terror,ora como instrumento político, ora como instrumento ideológico, em nível global.

O que se pretende com o presente estudo é analisar a atuação desses agentes não estatais violentos que surgem e ressurgem como desafios à capacidade regulatória estatal, causando o enfraquecimento do então inabalado modelo Westfaliano, invocando, inclusive, questões de segurança internacional,assim como investigar de que forma o Direito Internacional vem tratando do tema.

O método utilizado é o dedutivo, e a divisão do tema comporta três tópicos. $\mathrm{O}$ primeiro envolve a globalização, a transição de sociedade internacional para sociedade global, incluindo a tipologia dos atores, e a crescente importância dos emergentes não estatais. No segundo tópico, desenvolve-se a questão da violência e suas dimensões dentro do contexto de atuação dos atores não estatais, exemplificando as ações das organizações criminosas e as ações das organizações terroristas globais. E, finalmente, o terceiro ponto analisará a necessidade de avanço no aspecto jurídico que possibilite a limitação e regulamentação de ações provocadas por atores não estatais violentos.

O tema apresenta destacada relevância contemporânea, e deve merecer o interesse direto da academia para compreender não apenas a complexidade de suas relações, mas especialmente o impacto sobre a capacidade de regulação estatal.

\section{A FORMAÇÃO DA SOCIEDADE CONTEMPORÂNEA GLOBALIZADA E OS ATORES EMERGENTES}

No século XX, a ideia da sociedade internacional diferenciou-se pouco do que se propugnava nos séculos XVI e XVII. O que se apresenta ao longo de toda a história do moderno sistema de Estados, de um fronte a outro, são, em verdade, três tradições doutrinárias que tem competido entre si: a hobbesiana(ou realista), que considera a política internacional como um estado de guerra; a kantiana(ou universalista), que preconiza a atuação, na política internacional, de uma comunidade potencialmente voltada para a paz; e a grociana(ou internacionalista), para a qual a política internacional ocorre dentro de uma sociedade de Estados. Historia-se, por sua vez, que cada modelo tradicional passa a incorporar uma descrição da natureza da política internacional e um conjunto de prescrições sobre a conduta dos Estados(BULL, 2002, p. 32). Nos dizeres do autor, "[...] a interpretação realista 
ou hobbesiana da política internacional foi alimentada pelas duas guerras mundiais, assim como pela expansão da sociedade internacional para além dos seus limites originalmente europeus"; por sua vez,"[...] as interpretações universalistas ou kantianas foram alimentadas pelo esforço orientado para transcender o sistema de estados, pretendendo escapar da desordem e dos conflitos que o têm acompanhado nesse século e, ainda, das revoluções na Rússia e na China que deram novo alento às doutrinas da solidariedade transnacional" (BULL, 2002, p. 48).

Com efeito, "em diferentes fases históricas do sistema de estados, em distintos teatros geográficos do seu funcionamento, e nas políticas adotadas por diferentes estados e estadistas, um desses três elementos pode predominar sobre os outros" (BULL, 2002, p. 51). Resumidamente, para o autor, o sistema internacional moderno reflete todos os três elementos singularizados, respectivamente, pelas tradições hobbesiana, kantiana e grociana, quais sejam: a guerra e a disputa pelo poder entre os Estados; a cooperação e o intercâmbio regulado entre os Estados; e o conflito e a solidariedade transnacionais.

A ideia de interdependência política e econômica existente entre as nações ocidentais gerou muitas reflexões sobre a política, a economia e a cultura que conjecturavam uma separação entre as dimensões internas e externas nos campos local, nacional, internacional e global. O termo globalização, como um processo de interligação entre as esferas global e local, passou a ser efetivamente usado a partir das décadas de 60 e 70, quando,em um mundo interdependente, os acontecimentos mundiais no exterior rapidamente surtiam impacto internamente, enquanto os acontecimentos domésticos tinham consequências externas, como sustenta Held (2001, p. 08).

Nesse contexto, Santos(2002, p.55) observa que o mencionado fenômeno pode ser concebido como conjunto complexo de processos globalizantes que operam de maneira contraditória ou antagônica, e o produto desse processo está entreas dimensões global e local.Em simples palavras, trata-se da convergência dos momentos, em que os acontecimentos de um lugar passam a refletir nos demais.

O conceito de globalização, em sequência a esse raciocínio, refere-se às relações sociais em escala mundial, que ligam localidades distantes de tal maneira que acontecimentos locais são modelados por eventos ocorridos a muitas milhas de distância, e vice-versa, como interpreta Giddens (1991, p.69). 
A identificação do espaço internacional e das relações assim qualificadas entre internas e internacionais dar-se-á segundo o critério da localização formulado por Marcel Merle(1981, p. 111). Para o autor, são internacionais as transações ou fluxos que atravessam as fronteiras ou tendem a atravessá-las. Assim, suas vantagens mais evidentes são que, por um lado, "permite incluir nas relações internacionais as manifestações mais diversas tanto pela sua origem (pública ou privada), como pelo seu conteúdo (político, econômico, social, cultural, etc.)", e, por outro, que "leva em conta o fenômeno fundamental que constitui a divisão do mundo em Estados, já que torna precisamente a existência destes Estados, concretizada no terreno pela linha das fronteiras, condição necessária e suficiente para que uma relação possa ser qualificada como 'internacional'".

A transnacionalidade das relações e temas no cenário internacional contemporâneo, nesse ínterim, coloca em questionamento o significado de fronteiras soberanas e a possibilidade de atuação dos atores não-estatais.

A clássica distinção entre comunidade internacional e sociedade internacional tomou fôlego nas décadas de 40 e 50, cujas diferenças fundamentais formam um debate em que a característica mais marcante está no fato de que a comunidade contempla uma forma de ser do indivíduo nela incorporado, enquanto que a sociedade, ao contrário, representa uma forma de estar. Nas palavras de Oliveira (2003, p. 136), "na comunidade o indivíduo pertence", e, na "sociedade, apenas participa".

Autores como Arenal (1994, p.429), no âmbito da discussão sociológica, indagam se a disciplina das Relações Internacionais tem como objeto a comunidade internacional ou a sociedade internacional. Para o autor, "estamos frente a uma sociedade internacional, que apresenta traços característicos de comunidade internacional, ainda que esta não se tenha configurado plenamente como tal". Esse sentido de passagem - sociedade para comunidade internacional - ocorre paralelamente, de forma gradativa, evoluindo à forma de um Direito Internacional mais comunitário e social.

Ao observara sociedade mundial no final do século XX, Watson (1992, p. 101) constatou que um grande número de Estados apenas se aproximava nos aspectos reguladores, sem se sentirem ligados por valores e códigos morais. Nesse entendimento, Wight (1985, p.185) afirma que a comprovação mais evidente de que existe uma sociedade internacional é a existência do Direito Internacional, uma vez que toda sociedade possui seu direito, ou seja, um sistema de regras que estabelece os direitos e os deveres de seus membros. 
Hodiernamente, a firmeza da ideia de sociedade internacional como sociedade de Estados independentes e soberanos foi colocada em prova. O colapso das instituições tradicionais, o cosmopolitismo em expansão global, a nova ordem transnacional que governa os novos atores internacionais e a conduta dos Estados vem acompanhados pela revolução cientifico-tecnológica. Parte-se do pressuposto de que a sociedade internacional contemporânea abarca uma multiplicidade de interações entre indivíduos, empresas, grupos, organizações e o próprio Estado.

A complexificação da vida internacional, que percorre a transnacionalização dos fluxos econômicos e financeiros e das comunicações, criou condições para fortalecer, promover e incrementar a institucionalização da comunidade internacional. Nesse sentido, a sociedade internacional contemporânea "é compreendida como o conjunto de atores e cenários no qual se desenvolvem as relações internacionais" (OLSSON, 2003, p. 147).Para o autor, esses atores são "os sujeitos que realizam as relações ou fluxos, e os cenários ou meios são espaços específicos onde eles ocorrem; sua conduta, além disso, é orientada segundo papéis determinados". Por isso, prossegue o autor que, "do ponto de vista estrutural, a idéia de sociedade internacional pressupõe as ideias de atores ou agentes, de cenários ou meios, de papéis desempenhados e dos seus próprios fluxos ou relações"(OLSSON, 2003, p. 147).

Como primeira tarefa de delimitação do sentido da expressão "ator internacional" e sua inserção no âmbito das Relações Internacionais, tem-se o ator como o agente que atua ou desempenha um papel na sociedade internacional, participando do conjunto das relações sociais internacionais. Nos termos dessas colocações, qualquer entidade que desempenha um papel identificável nas relações internacionais é ator: “o Papa, o Secretário-Geral da ONU, o FMI são, portanto, atores" (EVANS, 1992. p. 5).

CalduchCervera(1991, p. 106) conceitua o ator como "todo grupo social que, considerado como unidade de decisão e atuação, participa eficaz e significativamente naquelas relações definidas previamente como fundamentais à estruturação e dinâmica de uma determinada sociedade internacional". Segundo essa interpretação, têm-se dois elementos centrais no referido conceito: o primeiro diz respeito à habilidade relacional, quer dizer, à condição de o ator associar-se às ideias de interação e influência mútua. O segundo elemento consubstancia-se na noção de que o ator deve participar de relações significativas. Ao definir quais são essas relações, condiciona-se, em pesquisa, a qualificação de atores internacionais segundo a compreensão proposta. 
A elaboração conceitual de Esther Barbé dá-se a partir da habilidade para mobilizar recursos e alcançar objetivos e da capacidade para exercer pressão e influência sobre os demais. Ao afastar-se de uma perspectiva fundada sobre bases jurídicas, percebe-se que Barbé(1995, p. 153) pauta-se por critérios funcionais, conceituando ator como a "unidade do sistema internacional (entidade, grupo, indivíduo) que possui habilidade para mobilizar os recursos que lhe permitam alcançar seus objetivos, que tem capacidade para exercer influências sobre outros atores do sistema e que goza de certa autonomia".

Giovanni Olsson(2003, p. 147)entende que aparições ocasionais ou efêmeras não têm o condão de descaracterizar o ator internacional. Para o autor, a continuidade não reside no fato de estar presente em todos os acontecimentos internacionais, mas em ter o potencial para tanto. Assim, parece razoável, diante da complexidade das relações e do cenário contemporâneo, prever que novos grupos organizados atuem internacionalmente emergindo em momentos históricos específicos.

Um conjunto de classificações é comumente estabelecido como ferramenta de compreensão dos papéis desempenhados, das funções exercidas, enfim, da atuação de cada ator. A primeira a que se faz referência foi elaborada por Marcel Merle(1981, p. 213), que criou uma tipologia ampliada e identificou, além dos Estados - ainda num lugar central -, três outros tipos de atores: as organizações internacionais; as organizações não governamentais; e as firmas multinacionais, hoje conhecidas como empresas ou corporações transnacionais.Nota-se que,nos dias atuais, sua abrangência tipológica não representa mais a realidade, haja vista o aumento da multiplicidade de atores que passaram a protagonizar inusitadas relações.

Ainda na década de 70, Richard Mansbach, Yale Ferguson e Donald Lampert identificaram essa multiplicidade de atores e definiram que ao menos seis tipos de atores interagiam entre si e compunham o sistema global contemporâneo. Para eles, ao lado dos Estados, estão os atores governamentais interestatais (organizações internacionais e supranacionais), atores não governamentais interestatais (organizações não governamentais e empresas transnacionais), atores governamentais não centrais (governos regionais, provinciais ou municipais), atores não governamentais intraestatais (grupos ou indivíduos que localizamse primariamente em um único Estado, mas são capazes de conduzir relações com outros atores autônomos que não seja seu próprio governo, a exemplo das fundações, organizações filantrópicas e partidos políticos), e, por fim, indivíduos que, em certas ocasiões, encontram- 
se aptos a comportarem-se com independência na arena global(MANSBACH, 1976, p. 3241).

A ampliação do tradicional sistema estatocêntrico para um complexo sistema global é o eixo fundador do pensamento desses autores, e a identificação da existência de tarefas globais efetuadas por atores globais é um elemento essencial dessa mudança(MANSBACH, 1976, p.273). É pertinentedizer ainda que, no lugar de um sistema estatocêntrico, os autores projetaram um modelo alternativo que chamaram de sistema do conglomerado complexo. Ao falarem em conglomerado, os autores fazem referência a "uma mistura de vários materiais ou elementos agrupados juntos sem assimilação" e cuja característica central "é a formação de alinhamentos situacionais específicos de diferentes tipos de atores usando uma variedade de recursos para alcançar objetivos complementares" (MANSBACH, 1976, p.42). Assim, afirmam que "em vez de uma hierarquia global com Estados soberanos no topo, podemos falar de uma 'rede de políticas globais' [ $a$ web of world politics] na qual os fluxos de bens, pessoas e ideias através das fronteiras nacionais produzem interdependência"(MANSBACH, 2000, p. 85).

Numa outra perspectiva de visualização dos fluxos internacionais, Odete Maria de Oliveira criou o denominado parâmetro eclético, concebendo a classificação dos atores a partir de três grandes grupos: tradicionais, novos e emergentes.No primeiro, por integrarem primária e tradicionalmente a disciplina, estão compreendidos os Estados; no segundo grupo, estão inseridas as organizações internacionais, organizações não governamentais e empresas transnacionais; e, por fim, fazem parte do terceiro os agentes que, mesmo sem uma existência consolidada e de todo reconhecida, ocupam um espaço que não pode ser ignorado, representando os presentes tempos contemporâneos (OLIVEIRA, 2011, p. 41).

$\mathrm{Na}$ perspectiva da autora, são emergentes “os movimentos sociais globais, grupos privados, grupos sociais, indivíduo, opinião pública, partidos políticos, associações religiosas, sindicatos, Igrejas, movimentos de libertação nacional, mídia, crime organizado, terrorismo, gênero, redes transnacionais e coalizões transnacionais, poderes erráticos" (OLIVEIRA, 2011, p. 42). Em síntese, as tipologias supracitadas são adequadas na medida de sua percepção multicêntrica da sociedade internacional.

As categorias estatais e não estatais são utilizadas para designar o conjunto de atores que atuam na sociedade internacional. Por conseguinte, no surgimento de novos atores, segundo as categorias estatais e não estatais, integram-se, de um lado, os Estados, em sua 
condição de atores tradicionais, e, de outro, os demais atores que, uma vez inseridos na sociedade global, interagem com os Estados e intervém nas suas relações internas e externas direta ou indiretamente, definindo contornos da ordem internacional. Consequentemente, enfraquecem o protagonismo unitário estatal, criam novas formas de distribuição e exercício do poder e influenciam a formação de uma agenda internacional muito ampla. A tipologia mais conveniente que separa atores estatais e não estatais considera que os atores não estatais "são entidades outras, que não os Estados-nação, que interagem no sistema político internacional" (TAYLOR, 1984, p. 20).

Essa tipologia coloca lado a lado os Estados e um vasto conjunto de atores autônomos que, em sua forma de ação e organização, transpõem as fronteiras nacionais, criando redes de participação que se encontram subsidiadas no espaço global.

Aquilo a que chamamos globalização é outra maneira de nos referirmos à sociedade em rede, ainda que de forma mais descritiva e menos analítica do que o conceito de sociedade em rede implica. Porém, conseguem, simultaneamente, comunicar e não comunicar. A sociedade em rede difunde-se por todo o mundo, mas não inclui todas as pessoas. De fato, neste início de século, “[...] nossa sociedade está construída em torno de fluxos: fluxos de capital; fluxos da informação; fluxos da tecnologia; fluxos de interação organizacional; fluxos de imagens, sons e símbolos. Fluxos não representam apenas um elemento da organização social: são a expressão dos processos que dominam nossa vida econômica"(CASTELLS, 1999, p. 18).

A transposição do estatocentrismo e a consequente identificação de novos atores ante a constatação do uso da rede, como canais múltiplos que conectam as sociedades, ultrapassam as fronteiras e estabelecem contatos de cooperação ou rivalidade, operando na sociedade internacional.

Nesse sentido, há uma "estranha realidade", composta pela "coexistência paradoxalmente simultânea de divergentes atores não estatais - tanto pacíficos quanto violentos, ao mesmo tempo detentores de cenários e protagonismos tão complexos e impactantes, ambos operando em redes globais" (OLIVEIRA, 2014, p. 40).

Ao mesmo tempo, atenta Manuel Castells que a comunicação em rede constitui uma profunda inovação na vida em sociedade, porque "a sua lógica chega a países de todo o planeta e difunde-se através do poder integrado nas redes globais de capital, bens, serviços, comunicação, informação, ciência e tecnologia, atômica, política e simbólica" (CASTELLS, 
1999, p. 501).

Por fim, o impacto da Revolução Tecnológica Informacional e o uso da rede mostram-se instrumentos suficientes para o reconhecimento do destacado protagonismo do poder e de influência alcançados pelos atores emergentes, tenham eles uma atuação pacífica ou violenta, nesse início do século XXI.

\section{A VIOLÊNCIA DOS ATORES GLOBAIS NÃO ESTATAIS NAS SUAS DIVERSAS MANIFESTAÇÕES}

No cenário do século XXI, observa-se a emergência de uma multiplicidade de variados atores não estatais. Entre eles, destacam-se os atores não estatais hoje reconhecidos como emergentes, os quais desconhecem vínculos de centralidade em suas extraordinárias mobilidades em rede,e enquadram-se nessa divisão relacional denominada atores não estatais violentos - objeto de estudo desta pesquisa -,caracterizados pela busca de enriquecimentos ilícitos e pela conquista de poder pela imposição do terror - como, por exemplo, as ações das organizações criminosas globais e as organizações terroristas globais.

As organizações criminosas e seus crimes organizados, por sua vez,operam em cadeias de densas redes clandestinas, interconectando-se. Para o alcance de suas finalidades, as organizações criminosas ditam as suas próprias regras, objetivando constituir e manter poderosos impérios de riqueza, força e poder. Assim, passam a desenvolver uma governança marginal. Trata-se de um Estado paralelo, exercendo extraordinária influência sobre as condições econômicas e políticas do mundo(OLIVEIRA, 2015, p. 15-42).

Algumas modalidades de crime organizado hoje no mundo são pirataria, contrabando, jogos de azar, extorsão, sequestro, corrupção, tráfico de drogas, tráfico de armas, falsificação de moedas, prostituição e comércio de produtos de roubo ou furto. Existem atualmente modalidades emergentes, tais como fraudes e desvio em cofres públicos, crimes cibernéticos, substâncias radioativas, tecnologia nuclear, espionagem industrial, biopirataria, lavagem de dinheiro, tráfico de pessoas, migrantes, trafico de órgãos e tecidos humanos e material de alta tecnologia (SCHELAVIN, 2011, p. 140-141).

E, nesse cenário de atores, as organizações terroristas globais, por sua vez, demonstram-se cada vez mais evidentes contemporaneamente devido à sua participação direta e indireta em alguns acontecimentos históricos recentes, constituindo-se em poderosos atores 
no cenário político, econômico, social e cultural.Atualmente, a sociedade global está apática por não ter soluções práticas a fim de conter fenômenos como o crescimento das organizações terroristas que estão cada vez mais fortalecidas por meio de sua atuação em um emaranhado de redes. Como preceitua Cretella Neto, o terrorismo é como um "inimigo sem rosto e um combatente sem pátria" (CRETELLA, 2008, p.113).

Oliveira (2016, p. 47) anota que, além das organizações terroristas,existe ainda a questão do crime organizado e relata que as redes são muito atrativas a esse tipo de atores, porque atuam quase sempre na clandestinidade, e, por conta disso, as redes e os crimes organizados são extremamente difíceis de combater. Nas palavras da autora, a era da informação instantânea produz novos desafios, porque, "ao mesmo tempo em que a comunicação em rede poderá proporcionar maior alcance e velocidade de fluxo às atividades dispersas dos agentes dos grupos terroristas, aumentando a capacidade e a rapidez das mensagens e suas respostas, igualmente poderá ocasionar grandes riscos para segurança, uma vez que os canais eletrônicos deixam rastros digitais, os quais poderão ser interceptados". Por isso, "tal tecnologia informacional representa arma de dois gumes para os atores violentos do terror. São exemplos de informações eletrônicas terroristas: do grupo Hamas e do próprio Osama Bin Laden, que ao caírem nas mãos das autoridades antiterrorismo, foram divulgadas pela imprensa e assim tornaram-se mais conhecidas" (OLIVEIRA, 2016, p. 60-61).

Não é possível identificar com certeza o momento exato do surgimento dessa última organização terrorista, mas alguns estudos apontam para o fato de a Al-Qaeda ter surgido por volta do ano de 1979, no Afeganistão, em apoio ao governo afegão (NOBREGA, 2016, p. 13).Cretella Neto (2008, p. 113) menciona que os atentados ocorridos após 11 de setembro de 2001 demonstraram o alto nível de organização estratégica dessa organização terrorista. Na continuidade, anota que "os terroristas que atacaram o World Trade Center eram, claramente,globalizados" (CRETELLA NETO, 2008, p. 114).

Mais além, verifica-se que as inter-relações dos atores não estatais violentos são construídas, organizadas e operadas em redes autônomas e descentralizadas, dispersas e clandestinas, o que comprova a existência de múltiplas estruturas organizativas que se unem para satisfazer os objetivos ilícitos almejados. A rede, portanto, constitui a própria lógica de ação de enriquecimentos delituosos, derivados das atuações criminosas dessas organizações e seus fluxos virtuais - fluidos e voláteis - materializados em cadeias de rede de redes(OLIVEIRA, 2016, p. 54). 
Como a finalidade das redes é facilitar fluxos de informação, conhecimento e comunicação, dessa forma, a virtualidade assume papel fundamental no debate do cenário e do protagonismo dos atores não estatais globais violentos.

Outro ponto fundamental a ser desenvolvido, e diretamente conectado ao anterior, é a questão da violência. Sabe-se que a violência está presente, de maneira direta ou indireta, na vida da sociedade e seus cidadãos.

Do ponto de vista etimológico, a violência vem "do latim violentia, de violentus(com ímpeto, furioso à força), entende-se o ato de força, a impetuosidade, o acometimento, a brutalidade, a veemência". Em regra, a violência resulta da ação, ou da força, irresistível, praticada na intenção de um objetivo, que não se teria sem ela (SILVA, 2002, p. 869).

Michaud (1989, p. 12-27), ao analisar a etimologia do termo, destacou que a problemática em definir o que seria violência está no núcleo da noção de violência,que é a força desmedida, sem consideração de valor. Por ser a força inerente ao ser humano, e o fato de este praticar múltiplas ações, é que podemos daí extrair alguns tipos de violência - como a política, a simbólica, a social, a física, entre outras -, que tanto podem ser praticadas pelo aparelho estatal quanto por indivíduos. Objetivamente, são formas de violência o assassinato, a tortura, a opressão, a criminalidade, o terrorismo, a guerra, a repressão, a da vida (provocada no indivíduo devido suas condições sociais), entre outras.

Para Pedroso (2002, p. 41), o termo violência é uma maneira acomodada de reunir todos os pensamentos que se referem à luta, ao conflito, ao controle, ou seja, à parte nebulosa que tormenta o corpo individual ou social. Assim, a violência pode ser dividida em vários seguimentos, tais como os conflitos sociais e políticos, repressão, terrorismo, guerras civis, tiranias, etc.

Para tanto, Michaud (1989, p. 12) ensina que, assim "como a noção de caos, de desordem radical, de transgressão, ela (violência), com efeito, envolve a ideia de uma distância em relação às normas e às regras que governam as situações ditas como naturais, normais ou legais".O autor acrescenta ainda que, por estar estreitamente ligada à ideia de transgressão às regras, a violência não está carregada apenas de valores negativos,mas também de valores positivos, "[...] porque ela representava a ruptura com as regras de uma sociedade condenada" (MICHAUD, 1989, p. 13).

Pedroso (2002, p. 40), através de um estudo, entende que no Brasil a violência é associada à estrutura do poder. Nesse ponto, aduz que "[...] a violência não é um mecanismo 
social e uma expressão da sociedade, mas uma resposta a um sistema". Ele explica melhor esse ponto, ao afirmar que "a violência está tão reificada quanto o poder, o sistema, o capitalismo, etc., como um elemento que é visto de modo isolado, individualizado, da sociedade na qual ela faz sua aparição". Essa disfuncionalidade decorre da ideia arraigada de como "se a violência e o violento fossem acidentes ou anomalias que um determinado tipo de sistema provoca e não uma possibilidade real e concreta de manifestação da sociedade brasileira" (PEDROSO, 2002, p. 40-41).

Ademais, a violência tida como tema nos discursos políticos ou nas preocupações da opinião pública traduz avaliações positivas e negativas. Michaud (1989, p. 14), assim, conclui dizendo que"[é] preciso estar pronto para admitir que não há discurso nem saber universal sobre a violência: cada sociedade está às voltas com a sua própria violência segundo seus próprios critérios e trata seus próprios problemas com maior ou menor êxito". Assim podemos dizer que não há padronização sobre a violência, fazendo cada sociedade seu próprio grau de avaliação de violência.

Com efeito, como entende Hannah Arendt (2001, p. 42),“a violência sempre pode destruir o poder; do cano de uma arma emerge o comando mais efetivo, resultando na mais perfeita e instantânea obediência. O que nunca emergirá daí é o poder". Assim, a partir dessa consideração, a autora define a distinção entre o poder e a violência: "O poder não precisa de justificação, sendo inerente a própria existência das comunidades políticas; o que ele realmente precisa é de legitimidade (...)". Mais adiante, diz que o "poder emerge onde quer que as pessoas se unam e hajam em concerto, mas a sua legitimidade deriva mais do estar junto inicial do que de qualquer ação que então possa seguir-se, [...] a violência pode ser justificável, mas nunca será legitimada" (ARENDT, 2001, p. 41).

Contudo, a transposição ao plano internacional da lógica reflexiva quanto à existência de um ator internacional de atuação violenta parte do reconhecimento de seu impulso pelo fenômeno da globalização. Com isso, o ator resiste paralelamente a uma presença soberana estatal - hodiernamente limitada, ora por se misturar a ela própria, ora por corroborar para esse enfraquecimento-, ou, como atenta Ferro (2012, p. 34),"[...] lembremos aqui o Poder corruptor de penetração das organizações criminosas nas estruturas do Poder Publico".

De todo modo, a complexidade que engloba a sociedade internacional contemporânea compõe a forma estruturalista e hierárquica do comando em rede e os efeitos 
de suas conexões violentas, o que eleva as organizações criminosas e terroristas ao patamar de influência dos qualificados atores internacionais não estatais violentos.

Contrários aos dogmas emanados pelo Estado-Nação, as organizações criminosas e terroristas permanecem em constante luta anárquica pelo poder, seja limitando a soberania estatal, seja controlando mecanismos de dominação aptos a majorar o enfraquecimento das competências historicamente delegadas ao Estado-Nação.

O Direito Internacional, anuindo premissas mais hodiernas, reconhece em algumas organizações internacionais e outros sujeitos de direito de âmbito global certos direitos e obrigações, mas a noção de ator não coincide com a de sujeito de direito. A desenvoltura aplicada para influenciar a sociedade internacional a obrar de acordo com suas pretensões é o elemento caracterizador dos atores internacionais, que passam a sofrer implicações de acordo com o grau de autonomia, habilidade e capacidade dos demais atores envolvidos(OLIVEIRA, 2016, p. 110).

Assim, os demandados da sociedade moderna são precários para explicar os desdobramentos na contemporaneidade. Apura-se que o exercício de poder se descolou do núcleo do governo, seja porque estes ultrapassam os limites do Estado-Nação(distanciamento entre Governo e Governança),ou seja ainda pelo fato de envolverem atores não estatais, pacíficos e/ou violentos, em toda sua dinâmica mosaica.

Pode-se afirmar, parafraseando Weber, que os atores não estatais violentos são detentores de um singular "monopólio da violência ilegítima", porque exercem seu poder ao condicionar o dominado à ilusão coletiva capaz de reconhecer sua liderança, como um governo legitimo àquele exercício.

Assim, questiona-se: não serão eles os novos atores da dialética política internacional? A linha histórica do pensamento humano, capaz de promover uma percepção de "Estado usurpado", decorre também da análise das causas e consequências da inserção do crime organizado nas mais diversificadas esferas da sociedade internacional em nível global.

Categorizar as organizações criminosas e/ou terroristas como atores internacionais não estatais violentos e demonstrar seu protagonismo através do poder da rede requer a analise da interação entre as próprias organizações criminosas e o sistema sociopolítico e econômico com que são confrontadas.

Ademais, a inexistência de um conceito satisfatório às organizações criminosas e às organizações terroristas legitima o convencimento da necessidade de um maior 
aprofundamento do assunto e a importância da produção desse estudo para a academia brasileira. Em particular, a enunciação de um conceito claro e preciso fomentaria a esperança da sociedade internacional em realizar o planejamento de estratégias e medidas politicocriminais adequadas ao controle do fenômeno da criminalidade organizada e da expansão do "terror franqueado".

Nesse aspecto, a complexidade e a capacidade de mutação desses grupos criminosos e terroristas não só abalam os pilares estabelecidos no projeto filosófico normativo da modernidade, como também as relações de poder entre os atores tradicionais da dialética política internacional. Por essa razão, a atuação dos atores não-estatais violentos evidencia-se em realidade incontestável, não podendo mais ser ignorada, principalmente quanto à relevância das questões que desvelam o campo do saber das Relações Internacionais, e, mais eminentemente, o do Direito Internacional.

\section{OS LIMITES DA REGULAÇÃO JURÍDICA DO ESTADO NA SOCIEDADE GLOBALIZADA}

A partir da emergência do fenômeno da globalização e da atual intensidade e forma com que esse fenômeno influencia nas mais diversas dimensões - política, social e econômica -, pode-se dizer que atualmente o direito estatal e a regulação social estão em crise:"Os avanços tecnológicos tornaram as fronteiras mais porosas. Os estados conservam a sua soberania, mas os governos sofreram uma erosão em sua autoridade" (COMMISSION ON GLOBAL GOVERNANCE, 1995, p. 11).

Hoje a maioria das dúvidas e preocupações dos juristas, cientistas, políticos e economistas estão centradas na regulação social e no direito, sob diversos aspectos.Discute-se a real eficácia da regulação tradicional através do Direito; a validade de outras formas de regulação social; a concepção da desregulamentação como apelo indireto e a criação de outro direito.

Discute-se, mais, que essa crise seria um movimento de desequilíbrio da soberania do Estado. Pode-se até cogitar outra forma de organização política global com uma tendência à perda de autoridade exclusiva dos Estados em reconhecer sua soberania, à transferência de autoridade para agentes ou instituições não-estatais e ao fim do poder do Estado sobre a coerção legítima. 
Isso faz com que nos encontremos diante de vários graus de intervenções, onde a crise do Direito está em reduzir o poder total do Estado no seu papel de produtor do Direito.

A partir daí, e dentre outros marcos teóricos, é necessário estudar os conceitos de direito estatal substituído, direito estatal suprido e direito estatal suplantado, como propostos por André-Jean Arnaud (1999, p. 151-193), que explica três momentos do direito nessa atual crise.

De acordo com o conceito de "direito estatal substituído", a produção do direito pode ser diversa do modelo tradicional até então conhecido, ou seja, do Estado enquanto um criador do Direito.O direito estatal pode ser substituído, por exemplo, por acordos regionais, que atualmente dominam os debates do direito em crise.Fala-se do ponto de vista do Direito Internacional: ao lado das normas propriamente ditas, existe toda uma normatividade que regula esses grupos e que transformam a paisagem da soberania nacional tradicional.

Além disso, essa crise do direito se expressa quando o direito é substituído (ao contrário dos acordos regionais que se situam acima do direito estatal), nesse caso, por instâncias que se situam abaixo dele. Como exemplo, temos a importância do papel desempenhado pelas corporações, códigos de conduta privados e o desenvolvimento de um direito negociado, entre outras questões.

O surgimento de novas formas de negociação - como a arbitragem, a conciliação e a mediação -é um fato marcante, as quais estão cada vez mais presentes nos sistemas jurídicos dos Estados.O Estado, ao mesmo tempo em que conserva o controle do conflito, delega a possibilidade de dizer o direito a um número maior de pessoas. Assim o fazendo, o Estado acaba concedendo aos cidadãos e instâncias locais a possibilidade dessa substituição.

Por sua vez, quando se fala em "Direito estatal suprido", está automaticamente se referindo à situação em que políticas públicas ou programas de ação tomam a dianteira do direito no sentido tradicional, na instalação de uma regulação social.

E, por fim, no tocante ao "Direito estatal suplantado",diz-se que o direito estatal corre o risco de ser concretamente suplantado por outros tipos de regulação global que escapam da regulação estatal.Um tema bem comum diz respeito ao surgimento dos mercados financeiros espontâneos. As companhias multinacionais escapam largamente da regulação tanto nacional como internacional, pelo conhecido fenômeno da elisão combinada dos sistemas jurídicos, em se aproveitam das maiores vantagens comparativas dinâmicas de cada regime nacional em uma área específica (normas ambientais, sociais e tributárias, por 
exemplo) em uma complexa combinação de operações e de instalação de unidades para multiplicar seus lucros e reduzir os custos ambientais, sociais e tributários.

Nesse contexto, o direito estatal mostra-se como uma estrutura cada vez mais ausente. Isso também pode ser observado na questão das formas alternativas de resolução de conflitos que funcionam fora da regulação estatal, escapando do controle do Estado. É uma segmentação do poder, uma vez que, na medida em que essa fragmentação coincide com os domínios de ação dos Estados, o poder se encontra fracionado em campos de regulação autônomos.

As formas de produção da regulação e as formas de produção do direito não deixam de ser afetadas em razão dessa fragmentação e dessa segmentação, resultando nesse atual estado de crise.

Atualmente, percebe-se uma sólida permanência das formas de produção do direito tradicionais. Nessas, infiltram-se tipos de produção jurídica que podemos qualificar como "pós-modernas".

Pode-se dizer, por fim, que estamos em meio a duas problemáticas muito diferentes nessa atual crise: uma, considerada tradicional e de origem moderna, relaciona-se com a noção de que a regulação social é feita primeiro pelo Direito e o Estado soberano teria um poder exclusivo sobre o direito; e outra, contemporânea e emergente, se baseia em novos pressupostos, afirmando que nem toda regulação social passa necessariamente pelo Direito, onde a melhor regulação social não é forçosamente o Direito em si, porque o Estado perde terreno na sua soberania, inclusive no que diz respeito ao direito.

\section{CONSIDERAÇÕES FINAIS}

Os cenários jurídico, político, cultural e econômico revelam-se hodiernamente como campos de notório destaque perante o ambiente global. A implantação e o desenvolvimento do conceito de globalização em tais cenários a partir da segunda metade do século XX vieram a acentuar ainda mais um olhar atento a tais cenários. Isso principalmente ante a emergência de um ambiente conexo e interdependente, seja no tocante aos Estados, seja no que se refere aos demais atores que hoje compõem o cenário internacional.

Nesse ínterim, entrementes a esse ambiente permeado pelas mais abrangentes relações, toma especial ênfase a discussão quanto à existência e atuação dos diversos atores 
existentes no campo das Relações Internacionais, sejam eles estatais ou não-estatais, violentos ou não violentos (pacíficos), denotando uma percepção cada vez maior acerca de um conceito de "poder".

Não obstante a existência de discussões quanto à real existência de tais atores - em especial no tocante à divisão entre atores violentos e pacíficos -, não é de se olvidar a posição de destaque à observância quanto aos atores que utilizam da força e da violência para fins de implantação de seus ideais. Cabe peculiar destaque aos denominados atores não-estatais, hoje principalmente motivados por fins culturais, econômicos e políticos de disseminação de suas ideologias.

Os exemplos de tais atores não pacíficos são muito variados. Eles estendem-se desde organizações criminosas motivadas pelo comércio ilegal - a título de exemplo -, até mesmo organizações terroristas. Hoje, estão em singular voga organizações desse estilo atuando continuamente perante o ambiente global e ameaçando, inclusive, a liberdade e a segurança difusas, tal como o que se visualiza a partir da análise de grupos como a Al-Qaeda, o Estado Islâmico e os mais diversos cartéis e máfias (principalmente de cunho armamentista).

Por sua vez, a confrontação à existência de uma sociedade global cada vez mais emaranhada em redes, assim como a atuação dos atores que a compõem - sejam eles estatais ou não-estatais, violentos ou pacíficos - somente acentua a necessidade de um olhar crítico à questão. Isso principalmente tendo em conta que a soberania dos Estados, até recentemente tida por absoluta, passa a ser limitada, dando vez a um conceito contemporaneamente muito em voga de "quebra de soberania", ou seja, de uma concessão cada vez maior pelos Estados soberanos de concessões e parcelas de sua soberania em favor de atores não-estatais ou de organizações internacionais com fins de garantia aos seus interesses econômicos e interdependentes. E, vale dizer, é desse ponto que emerge a discussão relativa à substituição do poder do Direito, notadamente de origem intra ou interestatal, para o entendimento e regulação dos diversos atores, para o poder de outros âmbitos distintos, em sua maioria de origem não-estatal.

Não obstante essa discussão jurídica, há que se ressaltar que tal abertura de poder pode trazer não apenas malefícios, mas também vantagens para a compreensão, regulação e pacificação do cenário global. A abertura com fins de reforço às Organizações Intergovernamentais (como a Organização das Nações Unidas (ONU), por exemplo) e diplomáticas, nesse contexto, possui o condão de trazer modos de resolução que não 
necessariamente impliquem em violência ou coerção. Isso, permite, por exemplo, introduzir modos não conflituais de resolução de conflitos em escala geral, tais como os métodos já consolidados da mediação, conciliação, arbitragem e negociações em geral.

Em um ambiente no qual diversas ideologias de cunho cultural tomam proporções significativas dentro de um contexto mundial, tal como o que ocorre com os já mencionados grupos da Al-Qaeda e do Estado Islâmico, que atuam de modo violento (terrorista) com fins de implantação de seus ideais religiosos, a realidade tem se demonstrado cada vez mais como possuidora de uma essência frágil e instável. E a resolução diplomática dos conflitos é, sem sombra de dúvidas, o meio mais propício de pacificação, embora dotado de suas complexidades.

A partir de uma visão crítica própria, como já se pôde notar, tem-se que o acima já referido reforço às Organizações Intergovernamentais e diplomáticas é o meio mais adequado de pacificação global, principalmente diante da emergência e preocupação geradas por tais atores não pacíficos, que, por vezes, tentam limitar a liberdade de escolha dos indivíduos através da violência e da coerção.

É claro que não há como olvidar que, contemporaneamente, são abundantes os exemplos de atores estatais que usam da violência e da coerção (notadamente motivada pelo seu potencial nuclear) para fins próprios individuais e egoísticos. Porém, não há como se partir de uma visão exclusivamente estatocentrista e retirar de enfoque a emergência dos então denominados "atores não-estatais violentos", porque inclusive possuem capacidade, na realidade atual, de ultrapassar o campo de vigilância dos Estados soberanos, causando danos imensuráveis. Aparentemente, como dito, somente por intermédio de uma relação conjunta entre atores é que a pacificação pode, ainda que parcialmente, se concretizar.

\section{REFERÊNCIAS}

ARENDT, Hannah. Sobre a violência. 3. ed. Tradução André Duarte. Rio de Janeiro: RelumeDumará, 2001.

ARNAUD, André-Jean. O direito entre modernidade e globalização: lições de filosofia do direito e do Estado. Tradução de Patrice Charles Wuillaume. Rio de janeiro: Renovar, 1999.

BARBÉ, Esther. Relaciones internacionales. Madrid: Tecnos, 1995.

BULL, Hedley. A sociedade anárquica. TraduçãoVicente Marotta RangelBrasília: Editora Universidade de Brasília, 2002. 
CRETELLA NETO, José. Terrorismo internacional: Inimigo sem rosto, combatente sem pátria. Campinas: Millennium, 2008.

CASTELlS, Manuel. A sociedade em rede. Tradução Roneide Venâncio Mojer. 4. ed. São Paulo: Paz e Terra, 1999, v. 1.

CALDUCH CERVERA, Rafael. Relaciones internacionales. Madrid: EdicionesCienciasSociales, 1991.

COMMISSION ON GLOBAL GOVERNANCE. Our global neighborhood. New York: Oxford University Press, 1995.

EVANS, Graham; NEWNHAM, Jeffrey. The dictionary of world politics: a reference guide to concepts, ideas and institutions. Hertfordshire: Harvester Wheatsheaf (a division of Simon \& Schuster International Group), 1992.

FERRO, Ana Luzia Almeida. Crime organizado e organizações criminosas mundiais. 1. ed. 2.reimp. Curitiba: Juruá, 2012.

GIDDENS, Anthony. As consequências da modernidade. Tradução Raul Fiker.São Paulo: Unesp, 1991, p.69-70.

HELD, David; MCGREW, Anthony. Prós e contra da globalização. Tradução Vera Ribeiro. Rio de Janeiro: Zahar, 2001.

MANSBACH, Richard W; FERGUSON, Yale H; LAMPERT, Donald E. The web of world politics: non state actors in the global system. New Jersey: Prentice-Hall;Englewood Cliffs, 1976.

MANSBACH, Richard W. The global puzzle: issues and actor in world politics. 3. ed. Boston: Houghton Mifflin Company, 2000.

MERLE, Marcel. Sociologia das relações internacionais. Tradução de Ivonne Jean. Brasília: Editora da Universidade de Brasília, 1981.

MICHAUD, Yves. A violência. Tradução Selvino Assmann. São Paulo: Ática, 1989.

NOBREGA, Carla. Análise estratégica da maior organização terrorista do século XXI.Disponível em: <https://www.repository.utl.pt/bitstream/10400.5/6182/3/Tese.pdf>. Acesso em: 09 mar. 2017.

OLIVEIRA, Odete Maria de; SILVA, Andréia Rosenir da. Gênero como possível ator das relações internacionais. In: OLIVEIRA, Odete Maria de (Org.). Relações internacionais: a questão de gênero. Ijuí: Unijuí, 2011.

Relações internacionais, direito e poder. Editora Unijuí. Ijuí: 2014. v. 1. 
Relações internacionais, direito e atores não estatais: delineamentos de fundamentação. In: OLIVEIRA, Odete Maria de (Org). Relações internacionais, direito e poder. Ijuí: Unijuí, 2004. v. 1.

. Notas de Introdução. In: Oliveira, Odete Maria de (Org.). Relações internacionais, direito e poder: o contraponto entre atores estatais e não estatais. Ijuí: Unijuí, 2015. v. 2. p.15-42.

(Org). Relações internacionais, direito e poder. Ijuí: Unijuí, 2016.

; ZEFERINO, Alisson. $\mathrm{O}$ protagonismo das Organizações Internacionais não Governamentais como atores não estatais em rede. In: OLIVEIRA, Odete Maria de (Org.). Relações internacionais, direito e poder: atores não estatais na era da rede global. Ijuí: Unijuí, 2016. v. 3.

OLSSON, Giovanni. Relações internacionais e seus atores na era da globalização. Curitiba: Juruá, 2003.

PEDROSO, Regina Célia. Violência e cidadania no Brasil: 500 anos de exclusão.2. ed. São Paulo: Ática, 2002.

SANTOS, Boaventura de Sousa (Org.). A globalização e as ciências sociais. 2. ed. São Paulo: Cortez Editora, 2002, p.55.

SCHELAVIN,José Ivan. A teia do crime organizado: Documentário: Força Nacional de Segurança Pública e Operação no Rio de Janeiro; Crime Organizado: "Poder Paralelo", "Modus Operandi" e meios de controle. São Paulo: Conceito Editorial, 2011.

SILVA, De Plácido e. Vocabulário jurídico. 20. ed. Rio de Janeiro: Forense, 2002.

TAYLOR, Phillip. Non state actors in international politics: from transregional to substate organizations. Colorado: Westview Press, 1984.

WATSON, Adam. The evolution of international society. Londres: Routledge, 1992.

WIGHT, Martin. A política do poder. Tradução de Carlos Sérgio Duarte. Brasília: Editora da Universidade de Brasília, 1985. 